\title{
Accuracy of patient recall of opportunistic smoking cessation advice in general practice
}

Jeanette Ward, Rob Sanson-Fisher

\begin{abstract}
Objective - To determine the accuracy of patient recall of a question about smoking in a specified consultation in general practice; the accuracy of smokers' recall of advice to stop smoking; and predictors of accurate recall.

Design - Analysis of 1075 audiotapes was compared blind with matching patient questionnaires administered after the consultation to calculate sensitivity and specificity for patient recall as a dichotomous variable. Predictors of recall were determined by logistic regression.

Setting - General practitioner training practices, New South Wales, Australia.

Subjects - Thirty-four trainees and consecutive samples of their patients 16-65 years of age

Results - Patient recall of a question about smoking had a high false positive rate of $21 \%$ but a sensitivity of $93 \%$. Smokers over-reported advice to stop smoking (specificity $82 \%$; sensitivity $92 \%$ ). Predictors of accuracy of a question about smoking included patient sex (women 1.58 times more likely than men to be accurate); smoking status (smokers 1.7 times as likely as non-smokers to be accurate); and interval since consultation (those who completed their questionnaires within a week were 1.84 times more likely to be accurate).

Conclusions - Patient recall is systematically biased towards over-reporting of a question about smoking status and, among smokers, of advice to quit. Although we recommend its continued application in health services evaluation, findings should be interpreted with caution, particularly if subjects are male or the interval between recall of smoking cessation advice and the occasion of service in which it might have occurred is considerably delayed.
\end{abstract}

(Tobacco Control 1996;5:110-113)

Key words: smoking cessation advice; patient recall; sensitivity; specificity

\section{Introduction}

Smoking cessation counselling by healthcare providers represents an important element in any comprehensive tobacco control strategy.
In particular, general practitioners are well placed to identify large numbers of smokers in their daily work and to counsel them to quit. ${ }^{2}$ When this is done, quit rates are significantly or better for individuals ${ }^{3}$ and communities, ${ }^{4}$ iv particularly if the advice is individualised and reinforced. ${ }^{5}$ Readiness to quit, as measured by a patient's stage-of-change, also can shift as a result of such advice. ${ }^{6}$

Patient recall by means of a selfadministered survey or interview is a feasible way to measure general practitioners' provision of smoking cessation advice. Rates based on patient recall have been used to determine the prevalence and predictors of smoking cessation advice by primary care providers at practice and population levels. ${ }^{7-10}$ as well as the effectiveness of training programmes and other strategies to increase the frequency and $\bar{c}$ effectiveness of such advice. ${ }^{11-13}$ In contrast to the relative abundance of such publications, however, few studies to validate patient recall have been published.

As part of the Stanford Five-City Project, all adult household residents of randomly selected households were asked to recall if 'they had ever received physician advice to stop smoking'. Of those stating in 1978 that they had ever been advised by a physician to quit smoking, 25\% reversed that answer in 1986 and stated that they had never been counselled to quit smoking. ${ }^{14}$ No 'gold standard' corroborating physician advice was used in this study, however. Another study that used patient recall to evaluate residency training in smoking cessation counselling demonstrated no correla- o tion between patient recall and resident $N$ self-report, although the latter was thought $\underset{\mathcal{C}}{\mathcal{S}}$ unlikely to represent a 'true' gold standard. ${ }^{15}$ In a study conducted in a tertiary-care hospital, ${ }^{16} 0$ videotaped consultations of outpatients with $\overparen{D}$ chronic obstructive airways disease were ? analysed and results compared with patient $\frac{0}{\circ}$ recall, elicited by interview 15 minutes after the $\stackrel{0}{\mathbb{D}}$ consultation. Smoking cessation advice was $\stackrel{\rho}{\oplus}$

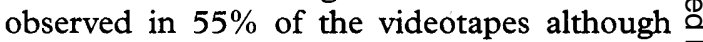
recalled by $89 \%$ of patients as having occurred. In a community study, ${ }^{17}$ smokers were $\delta$ randomly allocated to either an intervention or control group and telephoned three months later by researchers blind to group status. Only $60 \%$ of the intervention group recalled receiving advice from the physicians and only $51 \%$ recalled it as a message to quit. However, provision of smoking cessation advice to all smok- 
ers in the intervention group was not corroborated in this study.

Wilson and McDonald addressed some of the methodological weaknesses of these earlier studies. ${ }^{18}$ Patient recall of any discussion about smoking was elicited by self-completed questionnaire administered immediately after a consultation in general practice, which also had been audiotaped. Having demonstrated a sensitivity of patient recall of $74 \%$, small sample sizes precluded further statistical testing of different false positive rates among smokers and non-smokers of $11 \%$ and $4 \%$, respectively. Variables other than smoking status potentially influencing the accuracy of patient recall were not assessed. Nevertheless, they concluded that patient questionnaires remained the 'most feasible method' of assessing the provision of lifestyle advice in 'large scale research or audit studies'. ${ }^{18}$

Hence, we conducted this study with a larger sample size to determine the accuracy of patient recall of a question about smoking in a specified consultation and, for smokers, the accuracy of their recall not only of a question about smoking status but also of advice in that consultation to stop. Another aim of the study was to identify predictors of accurate recall of an opportunistic question about smoking status. Our 'gold standard' was an audiotape analysis of the consultation acquired as part of a larger project to evaluate postgraduate training.

\section{Method}

DATA COLLECTION

As described fully elsewhere ${ }^{19}$ consultations between consenting patients and postgraduate trainees were audiotaped at the beginning and end of their first-ever experience of three months in supervised general practice. As the distances separating these practices were large and the costs of face-to-face patient exit interviews excessive, self-administered questionnaires were mailed within two days of the consultation to adults aged 16-65 years to elicit patient recall. The questionnaire included questions about education, occupation, and marital status. Respondents were asked if, at the time of their consultation, they smoked more than 20 cigarettes a day, 1-20 cigarettes a day, were an occasional smoker, or smoked pipes or cigars. An affirmative answer to any of these options defined the patient as a smoker. All respondents were asked to recall if the trainee asked if they smoked and, for smokers only, whether the trainee had advised them to stop smoking. Three fixed responses were provided: 'yes', 'no', or 'can't remember'. To assist recall, the name of the trainee, day, and date of the relevant consultation were handwritten in a section before each question.

Four trained coders rated the audiotapes for a question about smoking or advice to stop smoking, using a detailed rating scale and coding manual, blind to patient report. Coders rated each behaviour as having either occurred or not occurred. The coder's ratings of the audiotape of the actual consultation represented the 'gold standard' against which patient recall as elicited in the follow-up questionnaire was compared.

\section{DATA ANALYSIS}

Sensitivity and specificity of patienfrecall as a dichotomous variable were calcutated from $2 \times 2$ tables by comparing resp@् patient questionnaires against amdiotapes. ${ }^{19}$ Responses for specific questions where patients indicated they 'couldn't remeniber' were treated as missing data. As no $\frac{\bar{\omega}}{\omega}$ significant changes in preventive care were de over time irrespective of training, $\frac{1}{2}$ data from all time periods and trainees were uึsed.

Using agreement as the outcon $\overrightarrow{f e}$ variable, predictors of accurate recall of an opportunistic question about smoking status for all adults and smokers were determined कुy logistic regression. ${ }^{20}$

The $\kappa$ values ${ }^{21}$ were calculated forinter-rater and intra-rater reliability of audiotane analysis.

\section{Results}

오

Thirty-four of 41 eligible trainee agreed to audiotape consultations at the beginning and end of their first three-month experience in general practice ( $80 \%$ consent rates 'Trainees' ages ranged from 25 to 31 years (median $=27$ years; mode $=26$ and 28 years); 19 were men and 15 were women. There was no overt response bias among trainees althoigh small numbers precluded meaningful $\stackrel{\circ}{\mathbb{D}}$ statistical analysis. During data collection, 50 adults aged 16-65 years attending the agreed to audiotaping ( $72 \%$ consent rate), resulting in 1362 usable audiotape्d consultations. Consenting patients did not differ from non-consenting patients on eithe? age $(z=$ $0.25, p>0.1)$ or $\operatorname{sex}\left(z=0.78, p>0 \frac{\pi}{4}\right)$ Of 1491 consenting adults who also suppled a name and address on the consent form, $1209(82 \%)$ returned follow-up questionnafires (750 females; 459 males). Almost two-tfirds (756 $(63 \%))$ were aged less than 40 years; 381 $(32 \%)$ were in full employmente and 153 $(13 \%)$ had a university or college qualification. Compared with non-responders, those who returned questionnaires were more jikely to be older $(z=4.8, p<0.05)$ or women? $(z=2.12$, $\mathrm{p}<0.05)$. Exactly half of the patjents who returned the questionnaire had completed it within eight days of the consultation (range = $1-63$ days; mode $=6$ days). Ofthe 1209 returned questionnaires, 1075 (41 $\$$ men; 656 women) had a matching audiotape, 9 ll of which were analysed. Of these, 451 g gdiotaped consultations had been conducted with patients who self-identified on the questionnaire as being smokers at the tir.me of the consultation with the trainee (179 क्षि men; 272 women).

ACCURACY OF RECALL б

Table 1 compares patient recall of about smoking status for all a patients, female patients, smokers, and non-smokers against the 'gold standard' of audiotape analysis using a $2 \times 2$ format. Overall prevalence of smoking cessation behaviour was low: a question about smoking occurred in 
Table 1 Accuracy of patient recall of a question from the trainee about smoking status *

\begin{tabular}{|c|c|c|c|c|c|}
\hline \multirow{2}{*}{ Patient recall } & & \multicolumn{4}{|c|}{ Audiotape } \\
\hline & & $\begin{array}{l}\text { Heard } \\
n\end{array}$ & $\%$ & $\begin{array}{l}\text { Not heard } \\
n\end{array}$ & $\%$ \\
\hline \multicolumn{6}{|c|}{$\begin{array}{l}\text { "Did the trainee ask you if } \\
\text { you smoke?" }\end{array}$} \\
\hline \multirow[t]{2}{*}{ All adults } & Yes & 187 & $93+$ & 148 & \\
\hline & No & 15 & & 547 & $79 \ddagger$ \\
\hline \multirow[t]{2}{*}{ Male patients } & Yes & 82 & $90 t$ & 60 & \\
\hline & No & 9 & & 178 & $75 \ddagger$ \\
\hline \multirow[t]{2}{*}{ Female patients } & Yes & 105 & $95 \dagger$ & 88 & \\
\hline & No & 6 & & 369 & $81 \ddagger$ \\
\hline \multirow[t]{2}{*}{ Smokers } & Yes & 90 & $98 \dagger$ & 49 & \\
\hline & No & 2 & & 198 & $80 \ddagger$ \\
\hline \multirow[t]{2}{*}{ Non-smokers } & Yes & 98 & $89+$ & 93 & \\
\hline & No & 12 & & 343 & $79 \ddagger$ \\
\hline
\end{tabular}

^ Responses for specific questions where patients indicated they "couldn't remember" were treated as missing data.

$\dagger$ Sensitivity,

$\ddagger$ Specificity.

only $29 \%$ of consultations in the sample and advice given to quit occurred in only $14 \%$ of those with smokers.

The specificity of $79 \%$ of patient recall of a question about smoking produced a false positive rate of $21 \%$. Sensitivity $(90 \%)$ of recall by male patients of an opportunistic question about smoking status was not significantly different from sensitivity (95\%) of female patient recall $(z=1.36, p>0.2)$. Specificity values of $75 \%$ and $81 \%$ for male and female patients, respectively, also were not significantly different ( $z=1.82, p=0.069)$. Smokers' recall of a trainee question about smoking status had a high sensitivity (98\%) but lower specificity $(80 \%)$. Sensitivity (89\%) of non-smokers' recall of a question about smoking status was significantly lower than that of smokers' recall $(\mathrm{z}=2.69, \mathrm{p}<0.001)$. Table 2 compares smokers' recall of advice from the trainee to 'quit' with the audiotape finding. Smokers' recall had a sensitivity of $92 \%$ and a specificity of $82 \%$.

PREDICTORS OF ACCURATE RECALL

Logistic regression was performed to ascertain predictors of accurate recall among adults of an opportunistic question about smoking status, using agreement as the primary variable. Eight variables included in the model were patient sex, age, education, smoking status, duration of the consultation $\quad<15$ minutes or $\geq 15$ minutes), delay time between consultation and completion of the questionnaire ( $<7$ days or $\geq 7$ days), trainee sex, and trainee stage of training. Table 3 shows that patients' sex, smoking status, and the delay between day of the consultation and completion of the questionnaire were significant predictors of accuracy. Specifically, patients who answered the questionnaire

Table 2 Accuracy of smokers' recall of the trainee advising to stop smoking

\begin{tabular}{|c|c|c|c|c|c|}
\hline \multirow[b]{2}{*}{ Patient recall } & & \multicolumn{4}{|c|}{ Audiotape } \\
\hline & & \multicolumn{2}{|c|}{ Heard } & \multicolumn{2}{|c|}{ Not heard } \\
\hline \multicolumn{6}{|c|}{$\begin{array}{l}\text { "Did the trainee advise you to } \\
\text { quit?" }\end{array}$} \\
\hline Smokers & $\begin{array}{l}\text { Yes } \\
\text { No }\end{array}$ & $\begin{array}{l}38 \\
3\end{array}$ & $92 \dagger$ & $\begin{array}{l}53 \\
237\end{array}$ & $82 \ddagger$ \\
\hline
\end{tabular}

within seven days of the consultation were nearly twice as likely to recall accurately whether the trainee had asked if they smoked. Smokers also were nearly twice as likely as응 non-smokers to recall accurately a question? about smoking status. Women were just over 1.5 times more likely than men to recall a음 question about smoking status accurately. Patient age, patient education level, trainee sex, $\stackrel{\mathscr{P}}{\stackrel{\rho}{+}}$ and trainee stage of training were not? significant predictors. The Mantel-Haenzel goodness-of-fit test $\left(\chi^{2}=7.11, \mathrm{df}=8, \mathrm{p}=0.525\right)$ indicated that the model fitted the data well.

RELIABILITY OF AUDIOTAPE ANALYSIS

The $\kappa$ values for inter-rater reliability of audiotape analysis for a question about smoking sta- $\vec{\omega}$ tus and advice to stop smoking were 0.94 and $\stackrel{?}{\vec{D}}$ 0.71 , respectively. The $\kappa$ values also were high $\because$ for intrarater reliability for each of the four $N$ coders for a question about smoking status $(0.98, \overrightarrow{\vec{O}}$ $0.98,1,1)$ and advice to stop $(0.74,1,1,1)$.

Discussion
Within the context of care provided by a $\vec{c}$ trainee in a specified consultation, patient ${ }^{\circledR}$ recall of components of opportunistic smoking $\vec{\ominus}$ cessation advice has high sensitivity. Specificity? is lower and also differs for patient subgroups, producing a substantial false positive rate of at least one in five. In contrast to the preliminary findings of McDonald and Wilson, ${ }^{18}$ smokers were more likely than non-smokers to be accu- $\stackrel{\mathbb{\Omega}}{\varrho}$ rate in recalling a question about smoking sta- $\overrightarrow{\overrightarrow{0}}$ tus. Nonetheless, their recall of advice to 'quit' remained prone to over-reporting. If used to evaluate clinical behaviour, patient recall may create an inflated sense of competence in smoking cessation activities.

Reasons to explain the high false positive rate might include the patient's eagerness to convey a good impression of the trainee's performance, an acquiescence bias, or bias 으 derived from respondents' perceptions of the socially desirable response. ${ }^{22}$ We did, however, emphasise in the questionnaire that it was important for the patient to think back carefully to the consultation and to be honest in answering the questions. In contrast, it $\frac{D}{2}$ might be argued that under-reporting could be expected, given the recognised limitations to $N$ patient recall of information about drugs and $N$ treatment options. ${ }^{23}$

The phenomenon of over-reporting appears to be attenuated if respondents are recalling

Table 3 Predictors of accuracy of patient recall of a question about smoking

\begin{tabular}{|c|c|c|c|c|}
\hline Variable & Coefficient & $O R$ & $95 \% C I$ & $p$ \\
\hline Patient sex & 0.457 & 1.58 & $1.16-2.14$ & $0.0027^{\star}$ \\
\hline $\begin{array}{c}\text { Trainee } \\
\text { stage }\end{array}$ & 0.028 & 1.03 & $0.90-1.18$ & 0.6873 \\
\hline $\begin{array}{l}\text { Sex of } \\
\text { trainee }\end{array}$ & -0.173 & 0.84 & $0.62-1.15$ & 0.2648 \\
\hline Patient age & 0.004 & 1.00 & $0.99-1.02$ & 0.4828 \\
\hline $\begin{array}{l}\text { Education } \\
\text { level }\end{array}$ & 0.206 & 1.23 & $0.86-1.75$ & 0.2459 \\
\hline Smoker & 0.529 & 1.70 & $1.25-2.30$ & $0.0005^{\star}$ \\
\hline Delay & 0.610 & 1.84 & $1.30-2.61$ & $0.0005^{\star}$ \\
\hline Duration & 0.222 & 1.25 & $0.91-1.71$ & 0.1571 \\
\hline
\end{tabular}

$\mathrm{OR}=$ odds ratio.

* Significant at 0.05 level. 
trainees' provision of smoking cessation advice some time after the consultation in question. It is surprising, however, that the duration of the consultation was not significantly associated with accuracy. Longer consultations are likely to involve more complex medical problems, extensive history-taking and exchange of information, possibly reducing the likelihood that patients will remember any one specific element of the consultation. This hypothesis was not borne out by the data. As this study shows that the patient's educational level is not significantly associated with accuracy, it is reassuring that patient recall has no more systematic bias if it is to be used to monitor the provision of smoking cessation advice to those socially and educationally disadvantaged.

Our study has its own potential methodological weaknesses. First, it may not be a representative assessment of patient recall due to unmeasured response bias among those returning questionnaires. Although an $82 \%$ response rate was achieved, patients who returned questionnaires were disproportionately older and over-representative of women. It is possible also that more educated patients returned the somewhat lengthy questionnaire, falsely inflating the accuracy of recall for the reference population. No data about the socioeconomic status of non-respondents were collected, however. Second, the potential to generalise the findings beyond the study setting of vocational training could be limited. Young trainees may be tentative about smoking cessation advice specifically and patient communication in general. Experienced general practitioners have an established relationship with their patients and may use different non-verbal and verbal cues to reinforce their preventive messages. ${ }^{24}$ There is some evidence to suggest that trainees see fewer patients and a different clinical population compared with supervisors. $^{25}$ To explore the potential influence of communication style and the patient's presenting problem, we recommend further studies to examine the accuracy of patient recall among patients of more experienced general practitioners. Further, our treatment of patient recall as a dichotomous variable by classifying responses of 'can't remember' as missing data may have introduced a potential bias if these patients receive different levels of smoking cessation advice. Although we found no evidence of such bias in our data, this may need examination in future research.

In summary, this study has confirmed that patient recall of opportunistic smoking cessation advice in the context of a recent consultation with a trainee is biased towards overreporting. In the absence of an alternative validated measure, patient recall likely will continue as an important measure of smoking cessation advice by medical practitioners but should be interpreted cautiously when the subjects are male or the time period between consultation and recall exceeds one week. We recommend further research to examine the accuracy of patient recall in non-training contexts to determine the relationships between accuracy of recall ant variables unmeasured in this study. Studiesoto evaluate the effect of alternative question c\&nstructions and different formats such as face-to-face or telephone surveys, especially those immediately after the consultation, also are needed.

The participation of trainees, their patients, an कipractice receptionists is acknowledged gratefully. We thank MFs Nancy Harding for diligent research assistance; $\mathrm{Mr}$ Stephe $\mathrm{Halpin}$ for statistical analysis; and Dr Jill Gordon, former State Director of the RACGP Training Program (New Soutb Wales), for organisational support and personal encouragent. This study was funded by grants awarded to Professor Sanson-Fisher from the New South Wales Cancer Council and the RACGP Training Program.

1 Chambers J, Killoran A, McNeill A, Reid D 1991;303:973-7.

2 Chapman S. General practitioner ant grammes: which one? Med $\mathcal{F}$ Aust 1990;152:508-9.

3 Coultas D. The physician's role in smokingressation. Clin Chest Med 1991;12:755-68. O

4 Rose G, Colwell L. Randomised controlled trial of anti-smoking advice: final (20 year) resutts. $\mathcal{F}$ Epidemiol Commun Health 1992;46:75-7.

5 Kottke T, Battista R, DeFriese G, Breek Attributes of successful smoking cessation interventiकns in medical practice. A meta-analysis of 39 controlled trials. $\mathcal{F} A M A$ 1988;259:2882-9.

6 Goldberg D, Hoffman A, Farinha M, et al. \$hysician delivery of smoking-cessation advice based on the stages-ofchange model. Am F Prev Med 1994;10:28-74.

7 Silagy C, Muir J, Coulter A, Thorogood MYudkin P, Roe L. Lifestyle advice in general practice: rates recalled by patients. BMF 1992;305:871-4.

8 Ockene J, Hosmer D, Williams J, et al. The్trelationship of patient characteristics to physician delivery of advice to stop smoking. F Gen Intern Med 1987;2:3\%40.

9 Cummings $K$, Giovino $G$, Sciandra $R$, Konigsberg $M$ Emont S. Physician advice to quit smokng: who gets it and who doesn't. Am $\mathcal{F}$ Prev Med 1987;3: $\overline{69}-75$.

10 Anda $R$, Remington $P$, Sienko D, Davis R Are physicians advising smokers to quit? The patient's perepective. $₹ A M A$ advising smokers to

11 Cummings $S$, Coates T, Richard R, et al. Tr席ing physicians in counseling about smoking cessation. Ann Intern Med 1989;110:640-7

12 Strecher V, O'Malley M, Villagra V, et al. Çan residents be trained to counsel patients about qufing smoking? Results from a randomised trial. $f$ Gen Intern Med

13 Dietrich A, O'Connor G, Keller A, Carney $\stackrel{\vec{B}}{\vec{B}}$ Levy D, Whaley F. Cancer: improving early detection and prevention. A community practice randomised tria $B M F$ 1992; 304:687-91.

14 Frank E, Altman D, Winkleby M, Fortmąn S. Physician influence on smoking cessation: the Stanford Five-City Project (abstract). PREVENTION 91 Corfference (Baltimore, Maryland), Washington, DC: Amegcan College of Preventive Medicine, 1991: 33.

15 McIlvain H, Susman J, Manners M, Davi $>$ C, Gilbert C. Improving smoking cessation counseling by family practice residents. $\mathcal{F}$ Fam Pract 1992;34:745-9.

16 Gerbert B, Hargreaves W. Measuring physifan behaviour. Med Care 1986;24:838-47.

17 Folsom A, Grimm R. Stop smoking advice A physicians: a feasible approach. Am F Pub Health 1987; त⿵⺆:849-50.

18 Wilson A, McDonald P. Comparison of peetent questionnaire, medical record and audiotape ingassessment of health promotion in general practice consultations. BMF 1994;309:1483-5.

19 Ward J, Sanson-Fisher RW. Does a three-ç⿰y workshop in preventive medicine change clinical belfviour? A randomised control trial. Prev Med 1996. In press.

20 Altman D. Practical statistics for medical restarch. London: Chapman \& Hall, 1991.

21 Byrt T, Bishop J, Carlin J. Bias, prevalence åुd kappa. 7 Clin Epidemiol 1993;46:423-9.

22 Furnham A. Response bias, social desirabil $\mathbb{D}$ and dissimulation. Personality and individual difference. 1986;7:385400.

23 Ley P. Patients' understanding and recall in Rinical communication failure. In: Pendleton D, Haslex- eds. Doctorpatient communication. London: Academic Bress, 1983:89 108.

24 Russell N, Roter D. Health promotion $\frac{\overline{0}}{x}$ ounselling of chronic disease patients in primary care visits. Am f Pub Health 1993;83:979-82.

25 Silagy C, Rutherford A. Clinical experience of a trainee in general practice. Aust Fam Phys 1988;17:594-7. 